\title{
The key to concordance
}

Jonathan Morrell

Medical Editor

Drugs in Context

DOI: http://dx.doi.org/10.7573/dic.212218

Citation: Morrell, J. The key to concordance. Drugs in Context: e212218. doi:10.7573/dic.212218

Copyright: this is an open access article published under the terms of the Creative Commons License Deed (CC BY-NC-ND 3.0) which allows you to share, copy, distribute and transmit the work provided it is properly attributed. You may not use this work for commercial purposes. For further information on commercial use, contact publisher@justmedicalmedia.com or go to werere.drugsincontext.com/copyright.

NB: This article was originally published by CSF Medical Communications Ltd (CSF) in Drugs in Context 2008;4(1):iv. Drugs in Context and all CSF copyrights were acquired by Just Medical Media Ltd in 2009. 


\section{THE KEY TO CONCORDANCE}

For patients who require multiple drug therapies, it would seem intuitive to prescribers and desirable to patients to use as few medications as possible. For best effect, long-term therapy requires the patient to persist with treatment (concordance), but this gets worse as the number of individual medicaments that have to be taken increases. Fixed dose combinations of drugs (FDCs) have been developed in order to simplify treatment and therefore improve concordance. They are widely used in asthma, diabetes, skin disease, analgesia and women's medicine. However, use of FDCs in the treatment of cardiovascular disease in general, and hypertension in particular, has been under a cloud for several decades, following arguments started by influential clinical pharmacologists. These arguments focused on the need for generic terminology (FDGs were often branded), occasional inappropriate dosing, the limited flexibility of FDCs in titration strategies, difficulties in identifying the component responsible for side effects, and the potential for pharmaceutical companies to manipulate costs. Disapproval in the UK has remained high, and in 2003 only $4 \%$ of prescriptions were for FDCs, compared with 500\% higher usage in Europe and the US. ${ }^{1}$ Despite this, more and more cardioprotective FDCs are becoming available for use in the management of hypertension, hyperlipidaemia and diabetes.

There is no doubt that patients prefer to take fewer pills. The number of pills prescribed correlates with an individual's perception of their illness, and patients are always keen to reduce their pill-taking burden. The ideal therapy for hypertension would therefore comprise once-daily dosing with as few tablets as possible. Well-tolerated FDCs have been shown to improve concordance, particularly in patients with chronic asymptomatic conditions such as hypertension (by $17-25 \%), 2,3$ and also where there are co-morbidities and in the elderly. Nowadays, FDCs are often flatpriced at the cost of the most expensive component and are therefore cheaper than their separate entities. There is often also a cost advantage for the patient who has to pay prescription charges.

Treatment pathways and goals for blood pressure management evolve from the findings of clinical trials, which have highlighted the inadequacy of monotherapy in achieving guideline values. In ASCOT, 77.8\% of patients needed two or more agents to control their blood pressure. ${ }^{4}$ This use of combination therapies gets more patients to target, particularly the low targets set for high-risk patients and those with diabetes or renal disease. ${ }^{5}$ In addition, combining two drugs at low dose is likely to cause fewer side effects than higher doses of a monotherapy. As a result, guidelines such as JNC7, ${ }^{6}$ $\mathrm{ESC} / \mathrm{ESH}^{7}$ and $\mathrm{BHS} / \mathrm{NICE}^{8}$ all recommend using appropriate combinations of antihypertensive drugs with different but complementary mechanisms of action. The JNG7 and ESC/ESH guidelines endorse the use of FDCs, as does the BHS when there is no cost disadvantage. Both the American and European guidelines suggest prescribing a two-drug FDC as an alternative starting strategy to monotherapy where blood pressure is significantly raised $\geq 160 / 100$ $\mathrm{mmHg}$ ), where there is target organ damage or where total cardiovascular risk is high. This is because blood pressure targets are attained earlier with combination therapies, which has been shown to improve outcomes in trials such as ASCOT and VALUE. ${ }^{9}$

The benefits and utility of available FDCs in cardiovascular disease prevention are challenging old views and are - appropriately - emerging with new roles in clinical practice, and clearly have a major contribution to make in the cardiovascular arena. In 2003, Wald and Law even suggested that a six-component 'polypill' could reduce cardiovascular disease by more than $80 \% .{ }^{10}$ Such an 'ultimate' FDC may seem far-fetched, but there is no doubt that FDCs are experiencing a renaissance, and not before time.

\section{Jonathan Morrell Medical Editor}

\section{REFERENCES}

1. FDC estimates from IMS. Hypertension 2003

2. Sturkenboom M, Picelli G, Dieleman J et al. $\mathcal{F}$ Hypertens 2005:23 (suppl2):S326

3. Wanovich R, Kerrish P, Gerbino P et al. Am $\mathcal{f}$ Hypertension 2004;17:233A

4. Dahlof B, Sever P, Poulter N et al. Lancet 2005;366:895906

5. Jamerson K. Am Soc Hypertension 2003; Scientific Sessions; May 21, Chicago

6. JNC 7. FAMA 2003;289:2560-72

7. ESH/ESC Taskforce. Eur Heart f 2007;28:1462-1536

8. BHS/NICE Clinical Guideline 34. London: NICE 2006. www.nice.org.uk/CG034

9. Julius S, Kjeldsen S, Weber M et al. Lancet 2004;363:2022-31

10. Wald N, Law M. BMJ 2003;326:1419 